\title{
TOMÁS DE AQUINO E O DIREITO DAS OBRIGAÇÕES: O QUE TÊM EM COMUM?
}

\author{
Renato José de Moraes ${ }^{1}$
}

\section{Resumo}

O objetivo deste trabalho é demonstrar que a filosofia medieval, concretamente a de Tomás de Aquino, traz uma série de conceitos e noções relacionados ao direito obrigacional que continuam de grande relevância nos dias de hoje. Institutos jurídicos modernos encontram fundamentações sólidas na ideia de justiça comutativa, elaborada por Aristóteles e desenvolvida por Tomás de Aquino. O direito medieval ensina lições preciosas para os juristas contemporâneos, e ele se encontrava de certo modo empapado pela estrutura filosófica da época. Por isso, o estudo dos escritos de Tomás de Aquino permite enxergar nossa teoria e nossa prática jurídicas de maneira diferente, com um termo de comparação enriquecedor. Além disso, Tomás propõe uma classificação bastante interessante a respeito dos delitos e dos contratos, que em vários pontos serve para os dias de hoje. Finalmente, a marca principal das obrigações, segundo a ótica dos medievais, seria a manutenção da igualdade material entre as partes envolvidas, conforme o estabelecido pela justiça comutativa. Essa igualdade é uma noção fundamental no direito contratual atual.

Palavras chave: Direito obrigacional; Tomás de Aquino; Justiça comutativa; Direito medieval

\section{INTRODUÇÃO}

Conhecer o direito medieval traz vantagens significativas para qualquer estudioso da arte jurídica. Por um lado, mostra-the maneiras diferentes de raciocinar os vários aspectos do jurídico, o que permite que analisemos criticamente, através da comparação, a teoria e prática do direito em que estamos imersos nos dias de hoje. Como sucede em outros campos do conhecimento, no direito corremos o perigo de nos acostumarmos com as soluções concretas e as construções abstratas predominantes em nosso tempo histórico, aceitando-as por uma espécie de inércia ou osmose. Evidentemente, esse acostumar-se é o contrário do espírito curioso e investigativo, que se espera de qualquer pesquisador sério.

Por outro lado, foi com os medievais, em torno do século XII, que efetivamente começou, de maneira íntegra, a ciência jurídica europeia (WIEACKER, 1980, p. 38). Por isso, retornar a eles é voltar às nossas origens, o que frequentemente é necessário para se iniciar uma renovação frutífera e consistente no pensamento jurídico. Muitas vezes, é preferível retornar ao ponto de partida, em vez de tentar encontrar a saída a partir de uma via

\footnotetext{
${ }^{1}$ Professor substituto na Faculdade de Direito da UFRJ, no Departamento de Teoria do Direito. Doutorado em Filosofia pela UFRJ (2015). E-mail: renatojmoraes@gmail.com
} 
equivocada. Por isso, aproveitar-se da sabedoria dos juristas medievais é no mínimo prudente, para entendermos melhor quem somos e porque chegamos ao ponto em que estamos, com suas virtudes e dificuldades.

Os juristas medievais foram influenciados pela escolástica, que era o modo de filosofar mais característico na época. Contudo, tal estilo de filosofia não era, de modo algum, uniforme; surpreende verificar as diferenças profundas existentes entre os vários professores de filosofia e teologia das diversas universidades nos séculos XII, XIII e XIV, inclusive a respeito de pontos tão centrais como a valorização do pensamento aristotélico e a relação entre a filosofia e a teologia.

Dentre as várias linhas filosóficas da época, especialmente importante foi a inaugurada por Tomás de Aquino, que tentou uma síntese entre o pensamento agostiniano, de longa e consagrada tradição entre os teólogos, com a obra de Aristóteles, cuja redescoberta completa no Ocidente promoveu um debate efervescente de ideias (MACINTYRE, 1988, p. 164-8). Sem ser vitorioso ou deter primazia nos anos seguintes à sua morte, o fato é que o pensamento tomista chegou a influenciar autores importantes, incluindo juristas como Baldo e Bartolo, dois dos principais pós-glosadores (GORDLEY, p. 39-40).

Neste trabalho, procuraremos examinar as observações de Tomás a respeito do direito dos contratos e dos delitos. Elas não servem como resumo do que os juristas medievais pensavam a respeito dos contratos, porque havia outros posicionamentos filosóficos esposados por grupos distintos. Porém, é inegável que a filosofia de Tomás serve para nos mostrar o modo de refletir do seu período, e nenhum outro filósofo ou teólogo da época pelo que sabemos - tratou tão profundamente do direito obrigacional. Examinar suas posições pode ser frutífero e fundamentar um saber crítico a respeito da teoria dos contratos e dos delitos, principalmente se tomarmos o cuidado de não "modernizar" ou "adaptar" a concepção tomista às teorias jurídicas atuais, mas busquemos ver em que elas podem ou não ser compatíveis.

Para tanto, iniciaremos com uma breve visão histórica da época em que Tomás escreve seus principais livros. Depois, examinaremos a concepção de direito que ele apresenta, onde tem papel fundamental a justiça. Esta virtude, por sua vez, será dividida em geral e particular, sendo que nesta última encontraremos o direito das obrigações. Sigamos esse trajeto.

\section{O RESSURGIMENTO DO DIREITO NA IDADE MÉDIA}

A relevância e força do direito medieval se explicam, em boa medida, por nele ter sido empregado, pela primeira vez, as artes auxiliares e disciplinadoras do pensamento e do raciocínio, que foram maturadas nas escolas junto às catedrais, aos conventos e aos palácios reais, de modo especial a partir do século IX. Tais artes eram as que formavam o trivium e o quadrivium. O primeiro era composto pela gramática, retórica e dialética; por sua vez, faziam parte do quadrivium a aritmética, a geometria, a astronomia e a música. 
Este foi o currículo fundamental de várias gerações de estudantes na época medieval, que posteriormente foi ensinado pelas várias Faculdades de Artes. Ser formado em Artes era um passo necessário para depois obter a graduação em direito (KENNY; PINBORG, 1982, p. 11-2).

A partir da dialética, desenvolveu-se a filosofia, incluindo a lógica. As demais artes liberais também auxiliaram no desabrochar da filosofia, que serviu como um fundamento importante de todas as disciplinas medievais, incluindo o direito e a teologia (MARENBON, 2010, p. 28-31).

Nas faculdades de direito, concretamente, a lógica foi utilizada com particular maestria pelos expoentes das escolas dos glosadores e dos pós-glosadores, que tiveram um papel fundamental no desenvolvimento do pensamento jurídico europeu. Eles aplicaram essas duas ciências da razão ao Corpus Iuris Civilis, que havia sido redescoberto algumas décadas antes e servia como fundamento principal do estudo jurídico. Por esse labor, eles chegaram a uma sistematização e organização da arte do direito superior à encontrada nos juristas romanos, seus modelos e inspiradores.

Para que não haja equívocos, é preciso esclarecer que não se trata da mesma sistematização da existente nas construções jurídicas de vários filósofos do direito contemporâneos, que buscam um ordenamento sem fissuras, sem antinomias ou lacunas. Esses filósofos empregam no direito o modelo das ciências naturais e sociais modernas, chegando a uma ciência neutra e com tendência forte ao formalismo.

Os medievais, ao contrário, lançaram mão da dialética e da lógica de sua época, que deixava maior espaço para o provável, o razoável, o preferível ou o perfectível, sem a pretensão de alcançar soluções definitivas, apodíticas ou deduzidas por um raciocínio formal perfeito. Da lógica aristotélica, aproveitavam principalmente o livro da Tópica, que estuda o pensamento racional a partir de opiniões verossímeis, ou do posicionamento dos mais doutos, e não tanto os Analíticos, que supõem verdades certas das quais se deduz juízos igualmente verdadeiros e claros (VILLEY, 2008, p. 263-9).

Assim, em Bolonha, a partir do século XII, surgiu algo que perdura até os dias de hoje, de maneira ininterrupta: o estudo profundo, consistente, desinteressado e organizado do direito. Talvez os medievais não entendessem o que fazemos hoje, ao tratar do jurídico, ou mesmo considerassem que estivéssemos totalmente equivocados. Ainda que isso pudesse ocorrer, haveria que aceitar a continuidade da ciência jurídica, que hoje segue outros moldes, mas continua dedicando-se ao direito com vigor e todos os dotes intelectuais disponíveis.

Com relação à Idade Média, há uma particularidade cultural interessante, que poderia nos servir de modelo. Nela, houve o impulso constante de aproveitar tudo o que viesse de outras culturas, fossem elas gregas, romanas, árabes ou judias. Em outras palavras, os medievais incluíram em sua própria cultura o que se lhes apresentasse como bom, porque se julgavam necessitados de complementação e de estudo. Sabiam-se inferiores, e tal consciência não os tornou ressentidos ou revoltados; antes, serviu de impulso para que pudessem aperfeiçoar- 
se e aprender dos outros (BRAGUE, 2008, p. 74-8).

Essa característica é particularmente marcante na filosofia, que naturalmente é um conhecimento que busca a universalidade. Por isso, não é difícil entender que os "artistas" e "teólogos", ou seja, os professores das faculdades de Artes e de Teologia, lançassem mão de escritos dos muçulmanos, judeus e pagãos para complementar sua própria filosofia. No direito, essa assimilação cultural mostra-se no respeito, até mesmo devoção, que os juristas dedicavam aos textos jurídicos dos romanos, em especial à compilação do Digesto. Apesar de ser obra de não-cristãos, isso não impediu em nada que ela fosse plenamente recepcionada e servisse de material para toda a construção do saber do direito de então.

Essa mentalidade de assimilação gerou como resultado um salto cultural admirável, que se mostrou marcante entre os séculos XI e XIV. Se antes a cultura europeia era reconhecidamente inferior à que existia em regiões muçulmanas, já a partir do século XII ela causará espanto em visitantes vindos da Síria, da Espanha ou de Damasco, pelo seu avanço e institucionalização (BRAGUE, 2008, p. 70-4). Tal institucionalização ficou caracterizada principalmente pela organização da Universidade, com pessoas dedicadas integralmente ao magistério e ao estudo (MARRONE, 2010, p. 53-5).

Conforme assinalado acima, Bolonha foi o centro inicial dos estudos jurídicos medievais. A primeira geração dos juristas que se dedicaram a eles foi chamada de glosadores, e por um motivo evidente: eles glosavam os textos do Corpus Iuris, em um trabalho meticuloso de interpretação de texto e de estudo da aplicação do mesmo. Com os glosadores, o direito torna-se novamente contemporâneo, em uma espécie de ressurreição que teve ecos duradouros na ciência jurídica europeia.

A geração seguinte de juristas medievais, apoiados na recepção do direito romano, foi a composta pelos pós-glosadores ou conciliaristas. Eles procurarão o sentido profundo por trás das aporias e incoerências existentes entre os doutrinadores romanos e sua interpretação variada das leis e dos institutos jurídicos.

Foi uma tarefa difícil e, às vezes, levada a cabo com certa artificialidade e forçando o sentido dos textos. Afinal, o Corpus Iuris Civilis abrangia escritos que originariamente foram elaborados no decorrer de vários séculos, em uma evolução de pensamento marcante entre os juristas de distintas épocas. Daí que apresente, necessariamente, opiniões discordantes, às vezes irreconciliáveis. Porém, os conciliaristas estavam convencidos de que, sob as discrepâncias, haveria um acordo profundo, que deveria ser trazido à tona, apreendido e ensinado. Através desses juristas, o direito de Justiniano tornou-se comum de toda Europa, passando a ser considerado a própria razão escrita no campo jurídico (WIEACKER, 1980, p. 80).

A evolução filosófica da época auxiliou bastante os juristas medievais, assim como a floração do direito canônico e a influência do pensamento cristão, que representou um abrandamento e humanização das disposições jurídicas romanas, especialmente as de direito público. Assim, chegou-se a um direito adequado à 
época medieval.

Vamos procurar compreender o direito contratual dos medievais de forma sintética, a fim de examinar se ele continua a nos influenciar nos dias de hoje. Para tanto, necessitamos voltar um passo e examinar a concepção de direito que prevaleceu no ressurgimento dos estudos jurídicos no século XII, que havia sido a herdada dos romanos clássicos.

\section{DEFINIÇÃO DE JUSTIÇA E DE DIREITO NO DIREITO MEDIEVAL}

No Digestoromano, encontramos a definição de Ulpiano a respeito da justiça:

A justiça é a vontade constante e perpétua de atribuir a cada um o seu direito. Os preceitos do direito são estes: viver honestamente, não lesar outrem, dar a cada um o seu. A jurisprudência é o conhecimento das coisas divinas e das humanas, a ciência do justo e do injusto (Dig.; 1.1.10)2.

Essa definição foi adotada pelos pensadores medievais, sendo que Tomás de Aquino aceita-a expressamente, sublinhando que ela está de acordo com a que Aristóteles formulou na Ética a Nicômaco (1. 5, c. 5; 1134, a, 1). A única alteração consistiria em substituir a expressão "vontade constante e perpétua", postulada por Ulpiano, pela aristotélica "hábito", que seria uma expressão mais exata para a definição da virtude (TOMÁS DE AQUINO, S.T., II Ia-IIae, q. 58, art. 1). Tal definição encontra-se no primeiro artigo do tratado sobre a justiça na

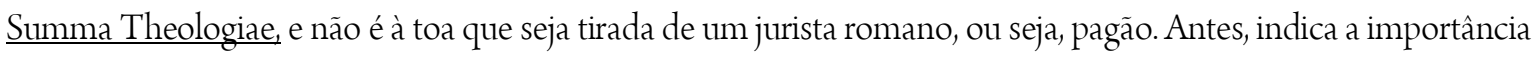
que Tomás reconhecia nos jurisconsultos romanos quando se tratava da justiça, o que também fica evidente pelo conhecimento que ele exibe sobre temas concretos de direito, conforme veremos adiante.

Conforme a definição de Ulpiano, o direito é o objeto da justiça. Repare-se que o jurisconsulto não afirma que a justiça atribuirá a cada um o que é seu por direito, como se o direito fosse uma norma que determinasse o que devesse ser feito; antes, o direito é a própria coisa justa, o objeto que será dado em uma relação de justiça. Tomás de Aquino entendeu e concordou com essa lição, que soa um pouco estranha aos ouvidos de hoje, e afirmou que o direito é a própria coisa justa:

Portanto, também este nome direito (ius) primeiro é assinalado para significar a própria coisa justa; posteriormente de modo derivado, é para a arte pela qual é conhecido o que seja justo; e depois, para significar o local em que o direito é realizado, como se diz que alguém comparece na justiça (in iure); depois também é chamado de direito o que é dado por aquele a cujo ofício pertence fazer justiça, mesmo que o que ele determine seja iníquo (TOMÁS DE AQUINO, S.T., II Ia-IIae, q. 57, a. 1, ad 1) ). $^{3}$.

Essa concepção do direito traz consigo uma série de implicações. Primeiro, o direito não é considerado

\footnotetext{
${ }^{2}$ Iustitia est constans et perpetua voluntas ius suum cuique tribuendi. Iuris praecepta sunt haec: honeste vivere, alterum non laedere, suum cuique tribuere. Iuris prudentia est divinarum atque humanarum rerum notitia, iusti atque iniusti scientia.

${ }^{3}$ Ita etiam hoc nomen ius primo impositum est ad significandum ipsam rem iustam; postmodum autem derivatum est ad artem qua cognoscitur quid sit iustum; et ulterius ad significandum locum in quo ius redditur, sicut dicitur aliquis comparere in iure; et ulterius dicitur etiam ius quod redditur ab eo ad cuius officium pertinet iustitiam facere, licet etiam id quod decernit sit iniquum.
} 
algo positivo, contraposto a um dever negativo. O direito pode ser uma multa, uma pena, um pagamento. É o objeto da ação justa, aquilo que cabe a alguém como algo próprio e ajustado, correto, reto, certo, direito. Tampouco é o poder sobre algo, mas esse próprio objeto - entendido em sentido amplo, que engloba bens materiais e imateriais, assim como competências, poderes e status - que é devido.

As leis são a regra do direito, mas não exatamente o direito. São caminhos pelos quais chegamos a ele, que é concreto e dá-se nos casos particulares. As leis são a regra escrita, seguida por quem produz a ação justa (TOMÁS DE AQUINO, S.T. II II-IIae q. 57 a. 1 ad 2).

Essa concepção quanto ao direito e à justiça não é exclusiva de Tomás, nem propriamente original. $\mathrm{O}$ pensador medieval tomou para si uma noção vigente em sua época, que havia sido formulada em seus contornos iniciais por Aristóteles e corroborada pela prática dos romanos. Portanto, podemos considerar que são definições comuns no mundo jurídico europeu em torno do século XIII. Além disso, é preciso tê-las em pauta para quando tratarmos especificamente dos contratos. Antes, porém, é necessário esclarecer algumas outras ideias vigentes no direito da época, que nos aproximarão de nosso tema central.

\section{DIREITO NATURAL E POSITIVO}

O direito, a coisa justa, é uma obra adequada a alguém conforme certa igualdade. As noções de adequação e igualdade são importantes. Algo pode ser adequado ao homem de duas maneiras. Primeira, pela própria natureza da coisa, como quando alguém entrega tanto para receber o mesmo tanto. Esse tipo de relação de igualdade, que advém da própria realidade, é chamada de direito natural.

Segunda, quando é adequado devido a um acordo ou acerto comum, tal quando alguém se considera satisfeito por receber tanto. Essa convenção pode ser particular, quando há um pacto entre pessoas privadas. Ou uma convenção pública, quando todo o povo consente em que algo será tido como adequado e proporcionado ao outro. Finalmente, pode ter seu fundamento no que ordena o príncipe, que cuida do povo e o gerencia. Esta segunda maneira é o direito positivo (TOMÁS DE AQUINO, S.T., IIa-IIae q. 57 a. 2 co.).

Esta diferenciação entre justo natural e positivo vem diretamente de Aristóteles (ARISTÓTELES, Ethic. l. V, c. 7; 1134, b, 18 - 1135, a 5), que a aplica para o justo político, isto é, o existente em uma cidade, e Tomás a expande e explicita. Os juristas romanos também fizeram uso dessa distinção, de forma bastante próxima à proposta por Aristóteles (Dig. 1.1.6 pr; 1.1.1.3; 1.1.1.4)

Convém salientar que o direito natural e o direito positivo não se contrapõem; antes, complementam-se. Em várias situações, é necessário ter ambos em conta, porque o ajuste, o justo, o direito precisará levar em conta a natureza das coisas e o acordo existente. A crítica do direito positivo apenas é possível porque há uma regra na natureza, que o homem pode descobrir com a sua inteligência. Por isso, ocorrerá de que se possa temperar a 
rigidez do direito positivo nos casos concretos, como a jurisprudência tanto demonstra.

Ao mesmo tempo, o direito natural carece habitualmente da determinação trazida pelo direito positivo. Se for justo penalizar alguém, o tanto de pena a ser aplicada tem que ser estabelecido antes por lei; o prazo para contestar uma ação é uma definição de algo necessário para o andamento dos processos, e assim por diante.

A antítese entre direito positivo e natural não era algo tido como usual para os juristas medievais, mas sim considerada uma falha, um equívoco. Caso a lei positiva fosse contrária à lei natural, então ela teria aparência de lei, mas não seria propriamente lei, porque lhe faltaria a causa final da noção de lei, que é promover a justiça. Seria lei em um sentido fraco, não pleno, conforme sugerem filósofos do direito que estudam Tomás nos dias de hoje (FINNIS, 1998, p. 272-3; 2011, p. 363-6).

\section{JUSTIÇA GERAL E PARTICULAR}

Se o justo pode ser natural ou positivo, de acordo com o aquilo que o determina, a virtude da justiça apresentará outra espécie de divisão, que a distingue em geral e particular. Note-se que não se está tratando do tipo de objeto, mas da espécie de relação de justiça. Ou seja, o objeto poderá ser tanto o justo natural quanto o positivo, mas o tipo justiça que leva a entregá-lo ao seu titular será geral ou particular.

Importa aqui estabelecer quem são os sujeitos envolvidos na relação de justiça: os indivíduos ou o todo social. A justiça geral regula o relacionamento do indivíduo para com o bem comum; ou seja, entre os cidadãos e a comunidade. Há, entre o indivíduo e a sociedade, uma relação similar a existente entre a parte e o todo. O bem do indivíduo enriquece e inclusive pertence de certo modo ao todo. Por isso, todas as virtudes do particular, assim como seus atos bons, mesmo que privados, podem representar uma melhora na comunidade e devem estar ordenados em função do bem comum. Nesse sentido, os atos de qualquer virtude podem pertencer à justiça, na medida em que esta orienta o homem ao bem comum e conta com os atos deste para ordenar a sociedade da melhor maneira possível (TOMÁS DE AQUINO, S.T., IIa-IIae, q. 58 , a. 5 co.).

Nesse sentido, não cabe um individualismo puro, pois o sujeito necessita considerar os efeitos das suas ações não apenas em si mesmo, mas também na sociedade da qual ele faz parte, da qual necessita para se desenvolver plenamente. Ademais, essa sociedade ou corpo político conta com a melhora dos indivíduos, seu crescimento em virtudes, para que ela mesma se aprimore.

Por sua vez, a justiça particular diz respeito às relações dos particulares entre si. Ela está incluída, de certo modo, na justiça geral; porém, enquanto esta trata diretamente do bem comum, e de forma mediata ao bem de cada pessoa em particular, a justiça particular diz respeito primariamente ao bem particular, e secundariamente ao 
bem comum ${ }^{4}$.

A matéria própria da justiça particular são as ações e coisas exteriores, enquanto por elas o homem é colocado em relação com outro, este também um particular (TOMÁS DE AQUINO, S.T., IIa-IIae, q. 58 , a. 7 co.). Não importam os sentimentos nem a intenção para definir qual seja a coisa justa, a ser atribuída pelo ato de justiça.

As virtudes sempre buscam um meio, um ponto ótimo entre dois defeitos opostos. No caso da justiça, esse meio é real, objetivo, não apenas de razão. Ou seja, é possível determinar, de fora, o que uma pessoa deve à outra, o que não sucede nas demais virtudes. Nelas, dependerá das condições do sujeito para determinar se ele bebeu demais, ou foi covarde, ou temerário.

Há uma objetividade naquilo devido em justiça. Assim é porque a matéria da justiça é a operação exterior, que em si mesma ou em relação à coisa de que trata, possui uma proporção devida à outra pessoa. O meio da justiça consiste em certa igualdade de proporção entre a coisa exterior com a pessoa exterior (TOMÁS DE AQUINO, S.T., IIa-Ilae, q. 58, a. 10 co.; HERVADA, 2008, p. 154-7). Devemos tal quantia àquela pessoa; podemos inclusive realizar uma cessão de crédito, que a dívida continua igual. $\mathrm{O}$ serviço tem que ser bem prestado, desde que se receba convenientemente por ele; tanto faz se há ou não simpatia pelo credor. São relações cujo meio, equilíbrio e igualdade são reais, objetivas, perceptíveis por terceiros externos às partes diretamente envolvidas.

\section{JUSTIÇA DISTRIBUTIVA E COMUTATIVA}

No âmbito da justiça particular, é possível descobrir outra distinção, entre justiça distributiva e justiça comutativa. Ambas têm por termo o particular, o indivíduo; o grupo social pode ser o destinatário da ação justa particular, mas nesse caso é tratado como se fosse um indivíduo, e não como coletividade. É o que se dá em vários contratos administrativos, por exemplo.

Tendo isso em conta, pode-se observar que, na justiça distributiva, há uma relação do todo para a parte, enquanto que, na comutativa, as relações são das partes entre si. Portanto, temos relações que viam o intercâmbio mútuo entre duas pessoas, compreendidas enquanto indivíduos ou particulares, e relações entre o que é comum, do grupo, e indivíduos desse mesmo grupo. Na justiça distributiva, há a distribuição dos bens comuns conforme a proporcionalidade; por sua vez, na justiça comutativa, a distribuição dá-se de acordo com a igualdade (TOMÁS DE AQUINO, S.T. IIa-IIae q. 61 a. 1 co.).

A justiça comutativa e a distributiva diferenciam-se não só pela unidade ou multiplicidade, no sentido de que é uma é apenas entre indivíduos, e a outra entre o grupo e um dos seus membros, mas sim pela natureza

\footnotetext{
${ }^{4}$ Interessantes, ainda que provavelmente exageradas, as ponderações de FINNIS, John (2011, p. 184-8) a respeito das distinções entre justiça geral, distributiva e comutativa.
} 
mesma da dívida. Afinal, como observa agudamente Tomás de Aquino, uma coisa é dever a alguém um bem comum, e outra, dever-lhe o que é próprio (TOMÁS DE AQUINO, S.T. IIa-IIae q. 61 a. 1 ad 5). No segundo caso, é mais nítida a distinção entre quem entrega e quem recebe o bem, a "propriedade" é mais evidente do que a que se dá entre o particular e o todo do qual ele é membro.

Assim, o meio real, objetivo, que é exatamente o direito, é considerado de maneira distinta no âmbito da justiça distributiva e no da comutativa. Na distributiva, é dado algo a uma pessoa privada enquanto aquilo que pertence inicialmente ao todo - seja poder, riqueza, honra ou obrigação de sustentar a comunidade - é devido à parte.

O quinhão do particular, no âmbito da justiça distributiva, será tanto maior quanto mais relevante for o protagonismo, a preeminência da parte dentro todo. Logo, se a pessoa desempenha um papel principal na comunidade, receberá uma maior parcela dos bens comuns do que a entregue a outros indivíduos.

É importante salientar que o critério para determinar quem seja o principal, o protagonista varia nas espécies de comunidade. Há as comunidades aristocráticas, quando consideram que o primeiro lugar pertencer às virtudes; oligárquicas, que se pautam pelas riquezas; democráticas, cuja base é a liberdade, e assim por diante. Inclusive, o que é principal em uma determinada circunstância não o será em outra, como sucede nas atribuições distribuídas em tempos de paz e nas de tempos de guerra, que podem ser bastante diferentes. Na paz, a prudência e a sabedoria são mais valorizadas que a força, o que pode se inverter no meio de um conflito bélico. Ademais, em uma mesma sociedade, na mesma época, haverá distintos pontos de vista, e de acordo com cada um deles, um será o critério a ser adotado como o mais importante.

Seja como for, o meio da justiça distributiva, aquilo que é devido a alguém, não é configurado segundo uma igualdade estrita de coisa a coisa, mas segundo a proporção das coisas em relação às pessoas. Tanto uma pessoa supera e excede a outra, quanto aquilo que é dado a uma pessoa deverá superar o que é dado à outra. Portanto, o meio da justiça distributiva é conforme uma igualdade geométrica, proporcional, tendo em conta a posição e importância do indivíduo dentro do grupo social, naquele aspecto concreto, e não segundo a quantidade. Ou seja, a distribuição dos cargos públicos, os salários dos agentes públicos, os impostos, as obrigações perante a cidade: tudo isso segue um padrão proporcional, não de mera igualdade quantitativa.

A justiça distributiva não existe apenas no grupo político, mas também se dá em outros grupos, como uma empresa, uma associação, ou qualquer coletividade. Também nela haverá prêmios diferentes, em virtude da maior ou menos relevância dos indivíduos em relação aos fins valorizados por aquele grupo.

Já na justiça comutativa, pode-se dizer que o modelo de suas relações é a compra e venda. Nela, é entregue algo a uma pessoa singular, em troca de uma coisa que dela que foi recebida. Há um dar e um receber mútuos, no qual é importante adequar coisa a coisa. Isto é, deve haver uma igualdade aritmética, que se define a 
partir de igualar o excesso de quantidade. Se dois sujeitos possuem cinco, e um deles toma uma unidade que pertencia ao outro, chegando a seis, a redução ao meio justo levará a que o que chegou a seis devolva um ao que ficara com quatro; assim, ambos voltarão ao equilíbrio (TOMÁS DE AQUINO, S.T., IIa-IIae q. 61 a. 2 co.).

Tanto a justiça distributiva quanto a comutativa têm a forma geral da igualdade. Numa, a igualdade é obtida mediante uma proporção geométrica; na outra, conforme uma proporção aritmética (TOMÁS DE AQUINO, S.T., IIa-Ilae q. 61 a. 2 ad 2).

\section{OS TIPOS DE TRANSAÇÕES}

Tomás não se limita a traçar uma perspectiva geral da justiça. Ele chegará a elaborar uma taxonomia das relações de justiça comutativa, com base no conhecimento que ele possuía de institutos jurídicos elaborados pelos romanos.

Para estabelecer quais são as transações reguladas pela justiça corretiva, iniciamos reconhecendo que a justiça trata de operações exteriores, que são distribuições e comutações. Ou seja, são usos de algo exterior, seja de coisas, de pessoas ou de operações. Exemplo de uso de coisas é quando alguém restitui a outro o que lhe pertence, dando a coisa de volta ao seu proprietário ou possuidor. O uso de pessoas, por sua vez, pode ser exemplificado quando alguém causa uma injúria na própria pessoa do homem, ferindo-o ou insultando-o. Por fim, o uso de operações é o que se caracteriza quando alguém exige justamente de outrem certa obra.

Tanto a justiça comutativa quanto a justiça distributiva terão como sua matéria as citadas coisas, pessoas e operações, pois essas três realidades podem ser tanto distribuídas quanto comutadas. Portanto, não é apenas por aí que diferenciaremos as distintas operações, e menos ainda a justiça comutativa da distributiva.

Porém, se consideramos como as matérias dessas justiças as ações principais pelas quais usamos da pessoa, das coisas e das obras, então alcançaremos matérias distintas. Transcendemos o mero objeto da operação - coisas, pessoas ou operações -, para chegar à própria operação de justiça. Nesse sentido, podemos afirmar que a ação da justiça distributiva é a de dirigir a distribuição; a da comutativa, dirigir as trocas entre duas pessoas. São realidades distintas, conforme assinalamos no ponto anterior, porque distribuir é tirar do todo para entregar a um indivíduo que é uma parte do todo, enquanto que a comutação versa sobre bens de pessoas totalmente distintas entre si.

Algumas transações, trocas e comutações da justiça comutativa são involuntárias, enquanto outras são voluntárias. É a mesma noção presente nas Institutas de Gaio (III, n. 88), provavelmente tirada da Ética a Nicômaco de Aristóteles (Ethic., 1. 5, c. 4; 1131, b, 25). No jurista romano, ele tratava da origem das obrigações; em Aristóteles, que foi seguido por Tomás, das comutações ou trocas. Esse é o fundamento da importante separação do direito das obrigações, entre direito contratual e responsabilidade civil, ou seja, contrato e delito 
(SCHULZ, 1960, p. 448).

Portanto, é possível afirmar que, em Tomás, o direito das obrigações é estudado - ainda que de forma indireta, pois se trata da obra de um teólogo, e não propriamente de um jurista - no campo da justiça comutativa. A qual é regida pela igualdade aritmética, ou seja, uma proporção de equivalência entre as partes, que devem se manter em equilíbrio em relação ao que perdem e ao que ganham. É o que será visto agora.

\section{As comutações involuntárias}

Tomás explica que as comutações, trocas ou intercâmbios são involuntários, nos casos em que alguém se utiliza, de modo forçado, de coisa, de pessoa ou de obra alheia. A partir disso, o pensador desenvolve uma teoria geral dos delitos. Assim, o modo forçado, que caracteriza a transação involuntária, pode ocorrer ocultamente, por fraude, ou de maneira manifesta, por violência. Tanto a fraude quanto a violência podem se dar na coisa da vítima, ou na própria pessoa desta, ou em pessoa próxima a ela.

Se a ação ilícita - o intercâmbio involuntário - for sobre alguma coisa, um bem material do lesado, poderemos ter um ilícito realizado ocultamente, com a tomada da coisa por outrem, o que se caracteriza como furto. Por outro lado, se o ilícito, a tomada da coisa, deu-se violenta e manifestamente, configurar-se-á o roubo ou a rapina. Portanto, furto e roubo são comutações involuntárias, com a tomada de uma coisa da vítima, de modo oculto ou violento, respectivamente.

Quando o ato danoso atinge a própria pessoa da vítima, ele poderá alcançá-la na sua integridade física (consistentiam, no original), ou na sua dignidade. Quanto à integridade da pessoa, a agressão pode ser oculta em casos como assassinatos ou ferimentos disfarçados, capciosos, e também através de envenenamento; será manifesta em situações como o assassinato público, o encarceramento, o açoitamento ou a mutilação de um membro. Como podemos perceber, são todos danos corporais, de maior ou menor grau.

Em relação à sua dignidade, alguém é lesado ocultamente pelo falso testemunho ou difamação, pelos quais alguém perde a sua boa fama. Manifestamente, pela acusação em juízo, ou cobrindo-o de injúrias diante de outros.

Por meio de uma pessoa próxima, alguém é lesado na esposa, na maioria das vezes ocultamente, pelo adultério. No empregado ou servo, quando alguém o suborna para que abandone seu amo; tais coisas também podem ser realizadas manifestamente.

Portanto, sem a pretensão de ser exaustivo, Tomás classifica os atos ilícitos por meio de dois critérios: a) quem é atingido pela comutação involuntária, ou seja, a pessoa, algo dela ou alguém próximo da vítima; b) se o delito foi oculto ou manifesto. Com isso, consegue abarcar a maior parte do campo do que hoje chamamos responsabilidade civil. 


\section{As comutações voluntárias}

As comutações voluntárias dão-se quando alguém transfere a outra pessoa livremente o que é seu, de forma consciente e sem coação. Se uma pessoa transmite a coisa para outra parte sem que surja um débito para esta, como na doação e em vários atos gratuitos, não se constitui então uma relação de justiça, mas de liberalidade. A questão do caráter contratual da doação aparece aqui de maneira latente; trata-se de um tema controverso, que certos autores decidem pela negativa do caráter contratual dessa liberalidade, que parece ser inclusive mais coerente com o espírito do direito romano e medieval (SCHULZ, 1960, p. 541).

De fato, a transferência voluntária diz respeito à justiça enquanto traz em si uma razão de débito. O que se dá de três modos. Primeiro, quando alguém transfere coisa sua para outrem, em compensação por ter recebido algo dessa pessoa. É o que sucede na compra e venda.

O segundo modo, quando alguém entrega sua coisa a outro, concedendo-lhe o uso da coisa, mas com a obrigação de devolvê-la. Quando esse uso da coisa é concedido gratuitamente, chama-se usufruto, se for um bem que frutifica; ou simplesmente mútuo ou comodato, tratando-se de coisas que não frutificam, como são o dinheiro e vasos de porcelana, por exemplo. Se nem o uso gratuito é concedido, mas uma contraprestação é exigida, a transação chama-se de locação e de arrendamento.

No terceiro modo, alguém entrega a sua coisa para recuperá-la posteriormente, não tendo por finalidade garantir o uso da coisa por quem a recebe. Se a finalidade é a conservação da coisa, temos o contrato de depósito; se o que se visava com a entrega do bem era garantir uma obrigação, surgem então o penhor e a fiança.

Em todas as transações descritas, sejam voluntárias, sejam involuntárias, encontramos a mesma razão de receber o meio da justiça, isto é, a quantia que cabe a uma parte, segundo a igualdade da compensação. Por isso, todas estas ações pertencem a uma espécie de justiça, a comutativa (IIa-Ilae q. 61 a. 3 co.), que também pode ser chamada de corretiva, por reequilibrar o que havia se tornado desigual por uma ação das partes envolvidas.

Quanto a isso, vale ressaltar que, na situação em que alguém causa dano aos bens de outro, contra a vontade deste, a ofensa seria maior que a simples compensação, se apenas a própria coisa fosse devolvida. Afinal, aquele que danificou outrem em sua propriedade, ele mesmo em nada seria danificado; por isso, ele deve ser punido e obrigado a restituir mais, também porque não prejudicou apenas o particular, mas a república, o corpo social, ao infringir a sua tutela de segurança. Notamos aqui a mistura entre o âmbito da indenização civil e da pena criminal, que não era tão distinto para os medievais e os romanos quanto é nos dias de hoje (FINNIS, 1998, p. 210).

Nas transações voluntárias, tampouco a justiça ocorreria se alguém desse sua coisa para receber uma coisa de outro, porque o bem de um pode ser maior que o do outro. Era o que Aristóteles chamava de reciprocidade, no sentido de que seria justo dar um sapato por um cavalo, o que o pensador grego considera 
evidentemente um absurdo (Ethic.. l. V, c. 5; 1132, b, 22 - 1133, b, 28). Assim, para permitir que as trocas entre bens de valores distintos pudessem ser levadas a cabo de maneira proporcional, inventou-se a moeda, como um meio termo que serve de medida para as demais coisas (TOMÁS DE AQUINO, S.T., IIa-Ilae q. 61 a. 4 co.).

\section{FRAUDE E USURA NAS TRANSAÇÕES VOLUNTÁRIAS}

Um dos elementos da teoria da justiça de Tomás de Aquino que mais pode estranhar a mentalidade contemporânea é o tratamento dispensado à usura e ao lucro nas transações comerciais. De acordo com os medievais e com Aristóteles, Tomás admitia o lucro em situações específicas, como uma remuneração por um trabalho, e não como uma vantagem que pudesse ser obtida a expensas de outro. Nesse sentido, ele pode ser interpretado como não capitalista, com o perdão pelo anacronismo desse tipo de afirmação. O desejo de adquirir, de acumular bens materiais não era visto como uma virtude, mas como um defeito que impediria a vida boa ${ }^{5}$. Estudemos esses pontos com mais detalhe.

A fraude na compra e venda configura-se ao pagar menos, ou cobrar mais, do que o valor da coisa vendida. Como a compra e venda foi introduzida para proveito comum das duas partes, cada uma precisando daquilo que a outra possui, então ela não deve ser mais onerosa para uma do que para a outra. Por isso, o contrato deve estabelecer uma igualdade no plano das coisas, dos bens. A moeda mede o preço, pois para isso foi inventada. Há aqui uma evidente presença da noção embrionária do justo preço.

Podemos falar de compra e venda, sem qualquer presença de fraude, ainda que acidentalmente resulte dela proveito para um e prejuízo para o outro. Por exemplo, quando alguém tem muita necessidade de um bem e o outro fica prejudicado, ao se privar do mesmo. Em tal caso, o justo preço deverá ser fixado tendo em conta não apenas a coisa vendida, mas também o dando que com a venda sofrerá o vendedor. Pode-se então licitamente vender uma mercadoria acima do seu valor em si mesma, embora não se venda acima do que vale para seu possuidor, ou seja, o vendedor.

Caso o comprador tire grande vantagem da mercadoria adquirida e o vendedor não sofra qualquer dano por se privar dela, não deve aumentar o preço. O proveito do comprador, nesse casos, não vem do vendedor, mas da condição em que se encontra o próprio comprador; e ninguém deve vender a outrem aquilo que não é seu, mas pode vender a ele o dano que porventura sofrer (TOMÁS DE AQUINO, S.T. II Ia-IIae q. 77 a. 1 co.).

Lembramos que Tomás está aqui tratando da moralidade da compra e venda, não da sua legalidade. A lei é para todos, não somente para os virtuosos. Por isso, ela não proíbe tudo o que vai contra a virtude, mas sim apenas aquilo que destruiria a convivência na sociedade. O resto é tido como lícito, não porque seja aprovado, mas

\footnotetext{
${ }^{5}$ A esse respeito, as observações instigantes de MacIntyre a respeito de Aristóteles, que podem ser aplicadas, mutatis mutandis, a Tomás de Aquino: MACINTYRE, 1988, p. 111-2.
} 
porque não é punido pela lei. Por isso, a lei permite que o vendedor venda o que é seu, supervalorizando o preço, ou que o comprador adquira abaixo do preço, salvo se houver excesso. De fato, a lei humana manda restituir se alguém foi enganado em mais da metade do preço justo, o que caracterizaria o instituto da lesão contratual.

Por outro lado, o preço justo não é rigorosamente determinado, mas consiste mais em certa estimação, de modo que uma pequena adição ou diminuição não parecem afetar a igualdade da justiça (TOMÁS DE AQUINO, S.T., IIa-Ilae q. 77 a. 1 ad 1).

O defeito na coisa vendida - seja na sua espécie, na sua quantidade ou na qualidade -, se conhecido previamente pelo vendedor, macula de fraude a compra e venda. Obriga então o vendedor à restituição frente ao comprador. De modo similar, se o vendedor não sabia do defeito, mas depois o descobriu, deve restituir o prejuízo do comprador, ainda que não tenha cometido pecado.

Também peca o comprador que compra determinada mercadoria por um preço muito abaixo do correto, porque o vendedor enganou-se em relação a ela. É o que se dá quando vende uma carne nobre, pensando que é uma de pouca qualidade. Também cabe aqui restituição, desta vez por parte do comprador (TOMÁS DE AQUINO, S.T. II ${ }^{a}$-IIae q. 77 a. 2 co.).

$\mathrm{O}$ vendedor não pode expor o comprador a dano ou a perigo, em virtude de um defeito oculto no bem vendido. Nesses casos, deve expor que há um problema no produto, ou abaixar o preço do mesmo em função da gravidade do defeito. Caso tenha abaixado o preço, e o defeito seja manifesto, não necessitaria salientar o problema, porque o comprador poderia então demandar uma diminuição excessiva no valor a ser pago (TOMÁS DE AQUINO, S.T. IIa-IIae q. 77 a. 3 co.). É de notar o bom senso e razoabilidade de várias das soluções de Tomás, próprias do direito de sua época.

Nesse sentido, suas afirmações sobre os comerciantes e o lucro são bastante interessantes, conforme indicado anteriormente. Os comerciantes exercem habitualmente a comutação de coisas, negociam-nas, e as comutações de coisas podem ser de dois tipos. No primeiro, é como natural e necessária, pois se faz a comutação de bens para satisfazer as necessidades da vida. Essa espécie de comutação não pertence propriamente aos negociantes, mas aos políticos e aos pais de família, aos quais cabe suprir as necessidades materiais da cidade ou da família. No segundo, a comutação é feita não em relação a coisas necessárias à vida, mas pela busca do lucro, e essa parece ser o próprio dos comerciantes. Segundo Aristóteles, o primeiro tipo de comutação é louvável, pois está a serviço de uma necessidade natural, enquanto o segundo é justamente reprovado, porque serve à cobiça de lucro, que não conhece fim e tende ao infinito.

Para Tomás, o lucro, em si mesmo, não importa algo de virtuoso ou de vicioso. Nada proíbe um lucro de ser ordenado a algo necessário ou honesto, e assim o comércio torna-se lícito. Como quando alguém busca, negociando, um lucro moderado, ordenado ao sustento da sua família ou ao auxílio dos indigentes; ou também 
quando alguém negocia pela utilidade pública, a fim de que não faltem coisas necessárias à vida da pátria. O lucro não deve ser buscado como fim, mas como remuneração do trabalho (TOMÁS DE AQUINO, S.T., IIa-IIae q. 77 a. 4 co.); então, ele é algo conforme a virtude e dentro da justiça. Estamos distante do desejo de aquisição e acumulação como bens por si mesmos, que caracterizam parte da sociedade de consumo; antes, encontramos a promoção de um tipo de existência mais austero, que não coloca nos bens materiais a finalidade principal da vida.

Vamos terminar com a análise da usura. Ela consiste em cobrar o preço do uso de um bem consumível, isto é, que vai se desfazendo à medida que vai sendo usado. Daí o nome usura. Ela seria injusta em si, porque se cobraria por algo que não existe: o uso do bem além do bem mesmo, o que apenas se pode dar com o que é infungível, não com algo fungível (TOMÁS DE AQUINO, S.T., IIa-IIae q. 78 a. 1 co.).

O direito justianeu defendia a mesma solução quanto à usura (JUSTINIANO, Inst., lib. 2, tit. 4), o que teria de ser adaptado aos dias de hoje. Por um lado, o dinheiro tem um papel diferente nas economias modernas do que aquele que exercia nos tempos antigos. Por isso, pode-se pensar em uma remuneração justa pelo seu emprego, admitindo-se assim os juros em um empréstimo.

Por outro lado, é de se suspeitar que nosso sistema econômico traz em si algo de profundamente injusto, quando chegar a remunerar o capital de maneira melhor que o trabalho e a produção. Se as soluções medievais para a usura, esposadas por Tomás e pelo direito da sua época, nos parecem arcaicas, talvez as nossas parecessem para ele absurdas e nocivas. A razão talvez esteja em um meio termo, que teria que ser buscado por juristas e economistas, que não se deixassem levar por jargões como "eficiência econômica" ou "exploração capitalista", que mais atrapalham do que ajudam uma discussão séria e aprofundada.

\section{CONCLUSÃO}

É oportuno estudar o direito medieval, bem como a base filosófica que muitas vezes estava por trás dele. Isso permite que repensemos o nosso direito, descobrindo talvez luzes e verdades que foram esquecidas com o passar do tempo.

Em relação ao direito obrigacional contemporâneo, não parece equivocado afirmar que, em muitos aspectos, ele está retornando a noções e soluções que seriam aceitas com facilidade pelos medievais, e que os civilistas do século XIX estranhariam como espúrias e prejudicais ao sistema da liberdade contratual e da autonomia da vontade. Nesse sentido, Wieacker está correto ao afirmar que o acontecimento mais importante no direito obrigacional do pós-Segunda Guerra Mundial "quanto a aspectos fundamentais foi talvez o regresso da jurisprudência ao princípio da equivalência material" (grifos no original) (WIEACKER, 1980, p. 599). Tal equivalência material pode ser equiparada, respeitados os devidos matizes, à igualdade da justiça comutativa de Aristóteles e Tomás de Aquino. 
Ela parece ser o fundamento de disposições importantes do nosso direito atual, como a previsão da lesão contratual (CC, art. 157); a correção pelo juiz da desproporção manifesta entre prestações surgida por motivos imprevisíveis (CC, art. 317); a resolução do contrato por onerosidade excessiva (CC, art. 478-480), a modificação das cláusulas de contratos de consumo que estabeleçam prestações desproporcionais ou sua revisão em razão de fatos supervenientes que as tornem excessivamente onerosas ( $\mathrm{CDC}$, art. $\left.6^{\circ}, \mathrm{V}\right)$, e outras figuras que dão preferência à igualdade material das prestações, em detrimento do estabelecido segundo uma interpretação formal da obrigação jurídica.

Estudar o direito de séculos atrás nos ajuda a perceber que reformas e avanços podem ser feitos olhando para experiências anteriores e adaptando-as para nossas circunstâncias. Não é necessário começar do zero, nem ficar presos aos sistemas atualmente vigentes. A quebra da ditadura do recente é um instrumento importante para os juristas, que foi empregado com sucesso em inúmeras ocasiões. Pensamos que pode ser novamente utilizado no direito das obrigações atual, observando as figuras do direito medieval e romano.

De certo modo, foi exatamente isso que fez o homem da Alta Idade Média, quando se apropriou de tudo que havia ao seu redor, quer viesse de cristãos, de pagãos ou muçulmanos, contemporâneos ou antigos, e fundou parte importante da cultura à qual pertencemos.

\title{
BIBLIOGRAFIA THOMAS AQUINAS AND THE LAW OF OBLIGATIONS: DO THEY HAVE ANYTHING IN COMMON?
}

\begin{abstract}
This paper aims to demonstrate that Medieval Philosophy, specifically Aquinas' philosophy, deals with some concepts and notions related to the law of obligations, which continue to be extremely relevant nowadays. Modern juridical institutes can find sound foundations in the idea of commutative justice, elaborated by Aristotle and developed by Aquinas. Medieval law teaches valuable lessons to the contemporaneous jurists, and this law was in an important sense dependent of the philosophical structure of its time. Therefore, studying the works of Thomas Aquinas leads us to see our juridical theory and practice from a different point, with a very rich model for comparison. Besides that, Thomas makes a very interesting classification of torts and contracts, which, in many points, is useful nowadays. Finally, the most important feature of the obligations, according to the medieval jurist, was the maintenance of material equality among the parts involved, according was established by commutative justice. Moreover, this equality is a fundamental notion in actual contractual law.
\end{abstract}

Keywords: Law of obligations; Thomas Aquinas; Commutative justice; Medieval Law 


\section{BIBLIOGRAFIA}

ARISTOTELES. Aristoteles graece: ex recensione Immanueles Bekkeri. Berolini: Academia Regia Borussica, 1831. volumen alterum. $676 \mathrm{p}$.

The complete works of Aristotle: the revised Oxford translation. Edited by BARNES, Jonathan. Princeton: Princeton University Press, 1991. t. 2: 1644 p.

BRAGUE, Rémi. Au moyen du Moyen Âge: philosophies médiévales en chrétienté, judaïsme et islam. 2. ed. Paris: Flammarion, 2008. $434 \mathrm{p}$.

FINNIS, John. AQUINAS: Moral, Political and Legal theory. Oxford: Oxford University Press, 1998. 386 p.

Natural law and natural rights. 2. ed. Oxford: Oxford University Press, $2011.494 \mathrm{p}$.

GORDLEY, James. The philosophical origins of modern contract doctrine. Oxford: Oxford University Press, $1991.264 \mathrm{p}$.

HERVADA, Javier. Lições propedêuticas de filosofia do direito. Tradução de Elza Maria Gasparotto; revisão técnica de Gilberto Callado de Oliveira. São Paulo: WMF Martins Fones, 2008. 450 p.

GAI. Institutionum commentarii quattuor. Submitted by Erich Schweizer-Ferrari from the Teubner edition of E. Seckel and B. Kuebler (Leipzig 1913). Disponível no sítio http://www.thelatinlibrary.com/gaius.html. Último acesso em 11 de agosto de 2016.

JUSTINIANI. Digesta. Disponível no sítio http://www.thelatinlibrary.com/justinian.html. Último acesso em 11 de agosto de 2016.

Institutionum. Disponível no sítio http://www.thelatinlibrary.com/justinian.html. Último acesso em 11 de agosto de 2016.

KENNY, Anthony; PINBORG, Jan. "Medieval philosophical literature". In: KRETZMAN, Norman; KENNY, Anthony; PINBORG, Jan (eds.). The Cambridge history of medieval philosophy: from the rediscovery of Aristotle to the disintegration of the scholasticism - 1100-1600. Cambridge: Cambridge University Press, 1982. p. $11-42$.

MACINTYRE, Alasdair. Whose justice? Which rationality? Notre Dame: University of Notre Dame Press, 1988. $412 \mathrm{p}$.

MARENBON, John. "The emergence of medieval Latin philosophy". In: PASNAU, Robert (ed.); DYKE, Christina van (ed. ass.). The Cambridge history of medieval philosophy. Cambridge: Cambridge University Press, 2010.p. 26-38.

MARRONE, Steven P. “The rise of the universities”. In: PASNAU, Robert (ed.); DYKE, Christina van (ed. ass.). The Cambridge history of medieval philosophy. Cambridge: Cambridge University Press, 2010. p. 50-62.

SCHULZ, Fritz. Derecho romano clásico. Barcelona, Bosch, 1960.620 p

Sancti THOMAE DE AQUINO. Summa Theologiae. Textum Leoninum Romae 1888 editum ac automato translatum a Roberto Busa SJ in taenias magneticas denuo recognovit Enrique Alarcón atque instruxit. Disponível no sítio www.corpusthomisticum.com, editado por ALARCÓN, Enrique. Último acesso em 22 de maio de 2014. 
AQUINO, Tomás De. Suma de teología: parte II-II (a). Edición dirigida por los regentes de estudios de las provincias dominicanas en España. Madrid: BAC, 1990.616 p.

VILLEY, Michel. Filosofia do direito. Tradução de Márcia Valéria Martinez de Aguiar. 2. ed. São Paulo: Martins Fontes, 2008. 466 p.

WIEACKER, Franz. História do direito privado moderno. Tradução de A. M. Botelho Hespanha. Lisboa: Calouste Gulbenkian, 1980.770 p.

Trabalho enviado em 24 de fevereiro de 2017. Aceito em 16 de abril de 2017. 